\title{
Corrigendum: An evolving perspective on the Pseudomonas aeruginosa orphan quorum sensing regulator QscR
}

\section{Sudha Chugani and Everett P. Greenberg*}

Department of Microbiology, University of Washington, Seattle, WA, USA

*Correspondence: epgreen@u.washington.edu

\section{Edited and reviewed by:}

Vittorio Venturi, International Centre for Genetic Engineering and Biotechnology, Italy

Keywords: bacterial communication, cell-cell signaling, transcription factors, sociomicrobiology, gene expression regulation

\section{A corrigendum on}

An evolving perspective on the Pseudomonas aeruginosa orphan quorum sensing regulator QscR

by Chugani, S., and Greenberg, E. P. (2014).

Front. Cell. Infect. Microbiol. 4:152. doi: 10.3389/fcimb.2014.00152

Figure 1 of the article by Chugani and Greenberg contains errors in the QscR sequence used in the alignment, which we hereby rectify. In the original figure the $\mathrm{N}$ terminal portion of QscR shows as dashes. We resubmit Figure 1 with corrections in the sequence.

Conflict of Interest Statement: The authors declare that the research was conducted in the absence of any commercial or financial relationships that could be construed as a potential conflict of interest.

Received: 05 December 2014; accepted: 05 December 2014; published online: 28 January 2015.

Citation: Chugani $S$ and Greenberg EP (2015)

Corrigendum: An evolving perspective on the
Pseudomonas aeruginosa orphan quorum sensing regulator QscR. Front. Cell. Infect. Microbiol. 4:181. doi: $10.3389 /$ fcimb. $^{2014.00181}$

This article was submitted to the journal Frontiers in Cellular and Infection Microbiology.

Copyright (c) 2015 Chugani and Greenberg. This is an open-access article distributed under the terms of the Creative Commons Attribution License (CC BY). The use, distribution or reproduction in other forums is permitted, provided the original author(s) or licensor are credited and that the original publication in this journal is cited, in accordance with accepted academic practice. No use, distribution or reproduction is permitted which does not comply with these terms. 


\begin{tabular}{|c|c|c|}
\hline $\begin{array}{l}\text { TraR } \\
\text { LuxR } \\
\text { LasR } \\
\text { RhlR } \\
\text { Methylosarcina } \\
\text { Acinetobacter } \\
\text { OscR } \\
\text { Burkholderia } \\
\text { BviR }\end{array}$ & 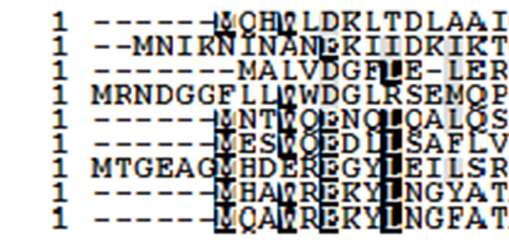 & 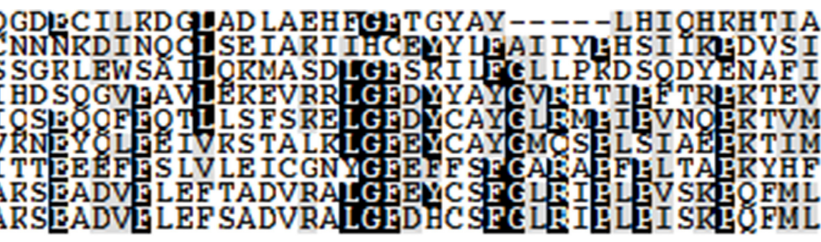 \\
\hline $\begin{array}{l}\text { TraR } \\
\text { LuxR } \\
\text { LasR } \\
\text { RhlR } \\
\text { Methylosarcina } \\
\text { Acinetobacter } \\
\text { OscR } \\
\text { Burkholderia } \\
\text { BviR }\end{array}$ & 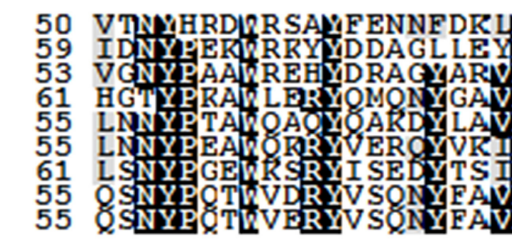 & 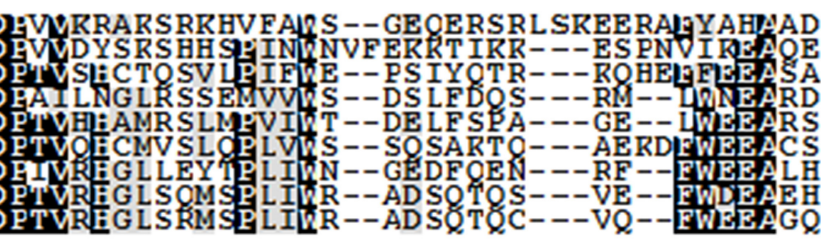 \\
\hline $\begin{array}{l}\text { TraR } \\
\text { LuxR } \\
\text { LasR } \\
\text { RhlR } \\
\text { Methylosarcina } \\
\text { Acinetobacter } \\
\text { OscR } \\
\text { Burkholderia } \\
\text { BviR }\end{array}$ & 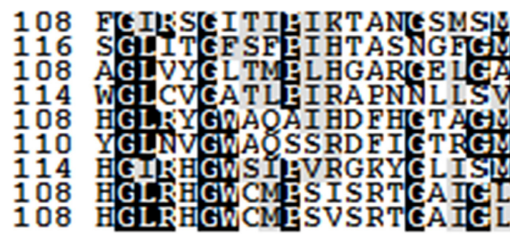 & 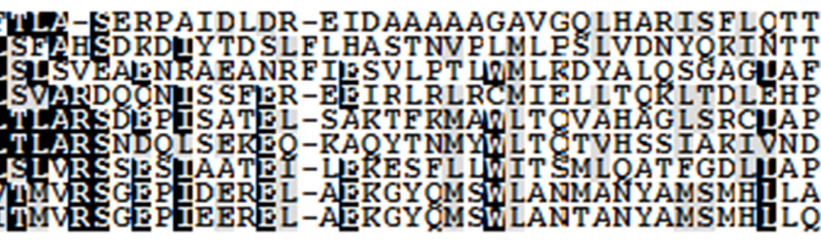 \\
\hline $\begin{array}{l}\text { TraR } \\
\text { LuxR } \\
\text { LasR } \\
\text { RhlR } \\
\text { Methylosarcina } \\
\text { Acinetobacter } \\
\text { OscR } \\
\text { Burkholderia } \\
\text { BviR }\end{array}$ & 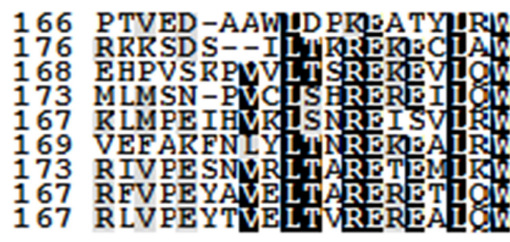 & 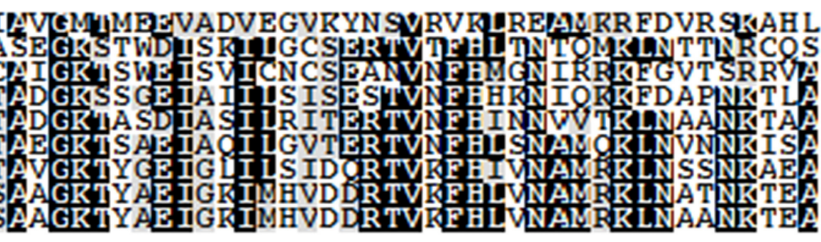 \\
\hline $\begin{array}{l}\text { TraR } \\
\text { LuxR } \\
\text { LasR } \\
\text { RhlR } \\
\text { Methylosarcina } \\
\text { Acinetobacter } \\
\text { OscR } \\
\text { Burkholderia } \\
\text { BviR }\end{array}$ & 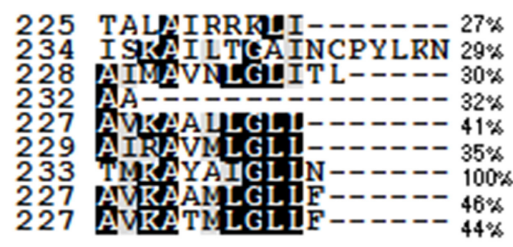 & \\
\hline \multicolumn{2}{|c|}{$\begin{array}{l}\text { FIGURE 1 | An alignment of the QscR sequence with previously } \\
\text { characterized LuxR homologs TraR, LuxR, RhIR, LasR, and BviR. We have } \\
\text { also included sequences of three ORFs annotated as LuxR-family } \\
\text { transcriptional regulators showing significant identity to OscR; } \\
\text { Methylosarcina lacus ( } 41 \% \text { identity), Burkholderia ambifaria ( } 46 \% \text { identity), } \\
\text { and Acinetobacter baumannii ( } 35 \% \text { identity). Conserved amino acids are } \\
\text { shaded in black. Gray shading indicates that } 100 \% \text { of the residues are similar } \\
\text { at that position. The numbers at the end of each sequence indicate the } \\
\text { percent identity with OscR. The alignment was generated by using the }\end{array}$} & $\begin{array}{l}\text { MUSCLE multiple sequence alignment program and the degree of residue } \\
\text { shading was determined by using Boxshade. The sequences used in the } \\
\text { alignment and their GenBank or NCBI Reference Sequence (RefSeq) } \\
\text { accession numbers are Agrobacterium tumefaciens TraR (RefSeq: } \\
\text { YP_001967610.1), V. fischeri LuxR (GenBank: M96844), P. aeruginosa LasR } \\
\text { (GenBank: M59425), P. aeruginosa RhIR (GenBank: L08962), Burkholderia } \\
\text { cepacia BviR (GenBank: AAK35156.1), Burkholderia ambifaria (RefSeq: } \\
\text { WP_006749592.1), Methylosarcina lacus (RefSeq: WP_024298126.1), and } \\
\text { Acinetobacter baumannii (GenBank: EXS59053.1). }\end{array}$ \\
\hline
\end{tabular}

